www.jmscr.igmpublication.org

Impact Factor (SJIF): 6.379

Index Copernicus Value: 71.58

ISSN (e)-2347-176x ISSN (p) 2455-0450

crossref DOI: https://dx.doi.org/10.18535/jmscr/v6i6.149

Journal Of Medical Science And Clinical Research

\title{
To Determine Predictors of Difficult Airway in Paediatric Age Group upto 6 Months of Age
}

\author{
Authors \\ Dr Pratibha Mudgal ${ }^{1}$, Dr Shilpee Kumari ${ }^{2}$, Dr Mridula Pawar ${ }^{3}$ \\ ${ }^{1}$ Senior Resident, Department of Anaesthesia, VMMC and Safdarjung Hospital, New Delhi \\ ${ }^{2}$ Senior Resident, Department of Anaesthesia, VMMC and Safdarjung Hospital, New Delhi \\ ${ }^{3}$ Senior Consultant, EMR Div, DGHS, Ministry of Health and Family Welfare, Nirman Bhawan, New Delhi

\section{Introduction} \\ ASA defines difficult airway as the situations in \\ which the conventionally trained anaesthesiologist \\ experiences difficulty with mask ventilation, \\ laryngoscopy and intubation. Techniques and \\ practices in airway management have long been \\ an important concern of ASA, as illustrated in \\ difficult airway guidelines ${ }^{[1]}$. Management of \\ airway is paramount to safe peri-operative care \\ and the following steps become necessary to \\ favourably affect outcome. \\ 1. Through airway history and physical \\ examination \\ 2. Process of maintaining oxygenation and \\ ventilation. \\ 3. Consideration of the ease of rapid tracheal \\ intubation \\ 4. Formation of management plans for use of \\ a supraglottic means of ventilation. \\ 5. Weighing the risk to the patient of failed \\ airway maneuvers. ${ }^{[2]}$ \\ The anatomically complex airway undergoes \\ growth and development and significant changes \\ in its size, shape and relation to the cervical spine \\ between infancy and childhood ${ }^{[3]}$. During \\ pediatric anesthesia, airway assessment and \\ management is paramount for the anesthetist. To \\ understand the comprehensive method of \\ assessment of pediatric airway, one has to know \\ the anatomy pertaining to airway as it develops \\ from birth, infancy and childhood. \\ Children have a proportionately large head and \\ occiput relative to body size. This causes neck \\ flexion, leading to difficulty in extension of neck \\ which helps to bring oral axis to align with \\ pharyngeal axis. \\ Relative large tongue decreases the size of the oral \\ cavity in children and more easily obstructs the \\ airway. In infants lying supine, the tongue tends to \\ flatten out against the soft palate in inspiration and \\ may remain in the same position for the passive \\ expiration through the nose ${ }^{[4]}$ \\ Anatomic differences between the paediatric and \\ adult airway: ${ }^{[5]}$ \\ 1. Proportionately smaller infant or child \\ larynx. \\ 2. Narrowest portion: cricoid cartilage in \\ infants/child; vocal folds in adult. \\ 3. Relative vertical location $\mathrm{C}_{3}, \mathrm{C}_{4}, \mathrm{C}_{5}$ in \\ infant or child; $\mathrm{C}_{4}, \mathrm{C}_{5}, \mathrm{C}_{6}$ in adults. \\ 4. Epiglottis longer, narrower and stiffer in \\ infant or child.
}


5. Aryepiglottic fold closer to midline in infant or child.

6. Vocal folds: anterior angle with respect to perpendicular axis of larynx in infant or child

7. Pliable laryngeal cartilage in infant and child

8. Mucosa more vulnerable to trauma in infant or child

There is no single factor that reliably predicts difficult airway in children as there can be many predictors of difficult airway in the same patient at the same time. We don't even know the normal values of many prediction criteria. ${ }^{[6]}$

Here in this study we plan to determine the predictors for difficult airway in children upto 6 months of age.

\section{Aims and Objectives of Research}

- To determine the correct predictors of difficult airway (Difficulty in mask ventilation, laryngoscopy and Intubation) in children upto 6 months of age.

- Primary outcome: predictors of difficult airway

- Secondary outcome: combination of values/ratios predicting difficulty airway

\section{Materials and Methods}

After due approval from the hospital ethical committee and informed written consent from parent or guardian, a observation study was conducted at Department of Anaesthesiology and Intensive care, VMMC \& Safdarjang hospital, of both the sexes, upto 6 months of age, ASA grade I \& II scheduled for elective surgery.

Pre-operative airway assessment was performed for all the patients by the same post graduate student of anaesthesia. Airway management was performed by an anaesthetist with a minimum of 3 years of experience.

\section{Inclusion Criteria}

- Children upto 6 months of age

- ASA grade I \& II
- Children requiring general anesthesia.

\section{Exclusion Criteria}

- Children > 6 months of age

- ASA grade III and IV

The parameters that were assessed in history

1. Frequent cough and URI

2. Fever

3. Nasal bleeding

4. Choking

5. Feeding problems

6. Drooling

7. Noisy breathing

8. Snoring

9. Mouth breathing

10. Sleep abnormalities

11. Change in voice

12. Hearing abnormalities

13. Previous difficulty in maintain airway

14. Performance in school

15. Birth history

The parameters that were assessed in examination

1. Abnormal facies

1. Pouting lips

2. Microstomia

3. Small nostrils

4. Beaked nose

5. Frontal bossing

6. Down slanting palpebral fissure

2. Low posterior hair line

3. Macroglossia

4. Dental examination

1. Malallignment

2. Prominent incisors

3. Loose teeth

4. Natal teeth

5 .Skin lesions

1. Pre auricular tags

2. Skin bullae

6. Nose examination

1. Patency of nasal airway

2. Nasal mass/polyp

7. Maxilla and mandible

1. Hypoplasia

2. Temporomandibular joint instability 
8. Neck examination

1. Short neck

2. Neck movement

3. Neck swelling

9. Spine examination

Kyphoscoliosis

10. Lymphadenopathy

11. Cyanosis

12. Microtia

\section{Measurements that were taken}

1. Length/height

1. Weight

2. Head circumference

3. Neck circumference

4. Chest circumference

5. Interalveolar distance

6. Distance between tragus and angle of mandible

7. Distance between angle of mandible and mentum

8. Hyomental distance

9. Distance between mentum and first neck crease

10. Distance between occipital protruberence to cervical prominance $\left(\mathrm{C}_{7}\right)$

\section{Assessment}

\begin{tabular}{|l|l|l|l|}
\hline MASK VENTILATION & 1 & 2 & 3 \\
\hline LARYNGOSCOPY & 1 & 2 & 3 \\
\hline INTUBATION & 1 & 2 & 3 \\
\hline
\end{tabular}

1- No difficulty

2- Difficulty could be overcome

3- Difficulty could not be overcome

\section{Observations and Results}

Demographic Data

\begin{tabular}{|l|c|c|}
\hline \hline Age (<6mnths) & LENGTH(in cm) & WEIGHT(in kg) \\
\hline Minimum & 58 & 4 \\
\hline Maximum & 93 & 10 \\
\hline Mean & 70.91 & 6.43 \\
\hline Std deviation & 9.66 & 1.23 \\
\hline
\end{tabular}

After assessing 59 patients of less than 6months of age, mean weight of $4.15 \pm 1.60 \mathrm{~kg}$, mean height of $60.8 \pm 12.33 \mathrm{~cm}$, was observed

\section{Mask Ventilation Difficulty}

\begin{tabular}{|c|c|c|}
\hline Age & Frequency & Percentage \\
\hline$<6$ mnths & 11 & 18.64 \\
\hline
\end{tabular}

Mask ventilation was possible for all the patients. Some difficulty was encountered in 11 patients (18.64\%) which could be managed.

\section{Laryngoscopy Difficulty}

\begin{tabular}{|l|l|l|}
\hline Age & Frequency & Percentage \\
\hline$<6$ mnths & 8 & 13.56 \\
\hline
\end{tabular}

Laryngoscopy was possible for all patients. Some difficulty was encountered in 8 patients $(13.56 \%)$ which was managed.

\section{Intubation Difficulty}

\begin{tabular}{|l|l|l|}
\hline Age & Frequency & Percentage \\
\hline$<6$ mnths & 8 & 13.56 \\
\hline
\end{tabular}

Difficulty in intubation was encountered in 8 patients $(13.56 \%)$ which could be managed.

Mean values of predictors used for airway assessment in upto 6 months of age:

Length $-60.8 \mathrm{~cm}$

Weight $-4.15 \mathrm{~kg}$

Head circumference- $37.83 \mathrm{~cm}$

Neck circumference $-21.94 \mathrm{~cm}$

Chest circumference- $37.37 \mathrm{~cm}$

Interalveolar distance- $2.91 \mathrm{~cm}$

Distance between tragus to angle of mandible$3 \mathrm{~cm}$

Distance between angle of mandible to mentum$5.76 \mathrm{~cm}$

Hyomental distance- $2.89 \mathrm{~cm}$

Distance between mentum to first neck crease$3.48 \mathrm{~cm}$

Neck length- $9.90 \mathrm{~cm}$ 


\begin{tabular}{|l|c|c|c|c|}
\hline Age(<6 months) & $\begin{array}{c}\text { Interalveolar } \\
\text { distance( in } \\
\text { cm) }\end{array}$ & $\begin{array}{c}\text { Dis b/w mentum } \\
\text { and first neck } \\
\text { crease(in cm) }\end{array}$ & $\begin{array}{c}\text { Ratio of height/dis } \\
\text { btw mentum and } \\
\text { first neck crease }\end{array}$ & $\begin{array}{c}\text { Neck } \\
\text { circumference(in } \\
\text { cm) }\end{array}$ \\
\hline Minimum & 2 & 1.5 & 28 & 18 \\
\hline Maximum & 4 & 4.5 & 19.77 & 42 \\
\hline Mean & 2.91 & 3.48 & 17.10 & 21.94 \\
\hline Std deviation & 0.37 & 0.62 & 21.25 & 3.71 \\
\hline
\end{tabular}

\section{Correlation of parameters of airway assessment of $<6 \mathrm{month}$ of age}

\begin{tabular}{|l|c|c|c|c|}
\hline & & p-value & Correlation value & Power \\
\hline Neck circumference & Weight & 0.0001 & 0.4855 & 98 \\
\hline Hyomental distance & Weight & 0.0018 & 0.3977 & 88 \\
\hline Dis b/w angle of mandible to mentum & Weight & 0.0032 & 0.378 & 85 \\
\hline Dis b/w mentum to first neck crease & Weight & 0.0005 & 0.441 & 94 \\
\hline Neck length & Weight & 0.0060 & 0.3534 & 79 \\
\hline Mask ventilation & Weight & 0.0059 & -0.3546 & 79 \\
\hline
\end{tabular}

\section{Discussion}

We assessed 59 patients up to 6 months of age preoperatively on the basis of history, physical examination and measurements (weight, length, head circumference, neck circumference, chest circumference, interalveolar distance, distance between tragus and angle of mandible, distance between angle of mandible to mentum, hyomental distance, distance between mentum to first neck crease, neck length and Mallampati class). The glottic view was then classified according to Cormack - Lehane classification during direct laryngoscopy and the difficulty with mask ventilation, laryngoscopy, and intubation was assessed.

In our study the mean weight and length in the age group less than 6 month was $4.15 \mathrm{~kg}$ and $60.8 \mathrm{~cm}$ respectively.

The average birth weight of neonates is about 3 $\mathrm{kg}$. During the first few days after birth, the newborn loses extracellular fluid equivalent to about $10 \%$ of the body weight. Most infants regain their birth weight by the age of 10 days. Subsequently they gain weight at the rate of approximately 25 to $30 \mathrm{~g}$ per day for the first 3 months of life. Thereafter they gain about $400 \mathrm{~g}$ weight every month, for the remaining part of the first year. An infant usually doubles $(6 \mathrm{~kg})$ his birth weight by the age 5 months. The birth weight triples $(9 \mathrm{~kg})$ at 1 year and is four times $(12 \mathrm{~kg})$ at 2 years of age. The weight of child at the age of three years is five times $(15 \mathrm{~kg})$ that of the birth weight. At 5 years, the expected weight is calculated by multiplying the birth weight by 6 $(18 \mathrm{~kg})$, at 7 years by $7(21 \mathrm{~kg}){ }^{[7]}$

The infant measures $50 \mathrm{~cm}$ at birth, $60 \mathrm{~cm}$ at 3 months, $70 \mathrm{~cm}$ at 9 months, $75 \mathrm{~cm}$ at 1 year and $90 \mathrm{~cm}$ at 2 years. A normal Indian child is $100 \mathrm{~cm}$ tall at the age of 4.5 years. Thereafter, the child gains $6 \mathrm{~cm}$ in height every year, until the age of 12 years that is $106 \mathrm{~cm}$ at the age of $5.5 y e a r s$ and $112 \mathrm{~cm}$ at the age of 6.5 years. ${ }^{[7]}$

In a study by Olubukola O. Nafiu, Constance C. Burke, in 2011, positively correlated neck circumference and other indices of obesity in children, with some adverse respiratory events in children aged 6 to 18 years undergoing noncardiac surgery. The mean value of neck circumference in this study was $31.9 \mathrm{~cm}$ for males and $29.8 \mathrm{~cm}$ for females. ${ }^{[8]}$

In our study the mean value of neck circumference in the age group less than 6 month was $21.94 \mathrm{~cm}$.

In another study by Aggarwal et al the mean value of neck circumference reported was $24.29 \mathrm{~cm}$. and were comparable with our study ${ }^{[9]}$

In the study by Aggarwal et al statistically significant correlation was found between neck circumference and mask ventilation (preparalysis $\mathrm{p}$ value $=.02, \mathrm{r}=-0.23$, power $63 \%$; post paralysis $\mathrm{p}$ value $=.002, r=-0.31$, power $88 \%$ ). However in our study neck circumference had significant correlation with Mallampati class and Cormack 
Lehane grade but not with difficulty in mask ventilation. $^{[9]}$

Neck circumference didn't show any significant change with age.

Neck length significantly changed with age.

Hyomental distance and distance between tragus and angle of mandible changed proportionally with age.

In our study, it was observed that in infants less than 6months of age the parameters of airway assessment correlated better with the weight than the age of the infant. Neck circumference ( $p$ $0.0001)$, hyomental distance ( $\mathrm{p}-0.0018)$, distance between angle of mandible to mentum (p-0.0032), distance between mentum to first neck crease ( $\mathrm{p}$ 0.0005) and neck length (p-0.006) correlated with weight than the age of the infant. The weight also correlated with the difficulty in mask ventilation (p-0.0059).

In infants less than 6 months of age difficult mask ventilation was associated with high Cormack Lehane grade (p-0.0084). Difficulty in mask ventilation was associated with difficult laryngoscopy (p-0.00) and difficulty in laryngoscopy was associated with difficult intubation ( $\mathrm{p}-0.033)$.

We could not find any literature to collaborate some of our findings as there are limited numbers of studies done this age group.

Difficulty in mask ventilation, laryngoscopy and intubation that was encountered could be managed due to the presence of experienced anesthetist while anesthetizing children of less than six months.

\section{Conclusion}

After analyzing the results of our study and thorough review of the available literature regarding difficult laryngoscopy and intubation, we reached to the conclusion that preoperative evaluation is important in the detection of difficult airway in children of less than six months.

In infants less than 6 months of age the parameters of airway assessment correlated better with the weight than the age of the infant. The weight also correlated with the difficulty in mask ventilation (p-0.0059). Difficult mask ventilation was associated with high Cormack Lehane grade ( $\mathrm{p}$ 0.0084) in this age group. Difficulty in mask ventilation was also associated with difficult laryngoscopy (p-0.00) and difficulty in laryngoscopy was associated with difficult intubation (p-0.033).

We could not find any literature to collaborate some of our findings as there are limited numbers of studies done in this age group.

Difficulty in mask ventilation, laryngoscopy and intubation was encountered and could be managed due to the presence of experienced anesthetist while anesthetizing children of less than six months.

We recommend that airway assessment, an experienced anesthestist and anticipation of difficult airway is of paramount importance in the age group less than 6 months and further studies are required to be done in this age group to predict difficult airway.

\section{Summary}

Anatomically airway undergoes growth and development and significant changes in its size, shape between infancy and childhood. During paediatric anaesthesia, airway assessment and management is paramount for the anaesthetist. To understand the comprehensive method of assessment of paediatric airway, one has to know the anatomy pertaining to airway as it develops from birth, infancy and childhood.

We assessed 59 paediatric patients up to 6 months preoperatively on the basis of history, examination and measurements of certain parameters to identify difficult airway.

We aimed at determining the predictors of difficult airway or combination of values/ratios for predicting difficult airway.

The study was conducted on ASA grade I and II patients, scheduled for paediatric surgery under general anaesthesia. Preoperative measurements [Length/height, Weight, Head circumference, Neck circumference, Chest circumference, 
Interalveolar distance, Distance between tragus and angle of mandible, Distance between angle of mandible and mentum, Hyomental distance, Distance between mentum and first neck crease and Distance between occipital protuberance to cervical prominence $\left(\mathrm{C}_{7}\right)$ ] were taken by the same under graduate and airway management was performed by an anaesthetist with a minimum of 3 years of experience.

Difficulty in mask ventilation, laryngoscopy and intubation was graded as 1(no difficulty), 2(difficulty that could be overcome) and 3(difficulty couldn't be overcome).

Grade 2 difficulty in mask ventilation was encountered in age group less than 6months (18.64\%). Grade 3 difficulty was not encountered in our study population.

Grade 2 difficulty in laryngoscopy was encountered in age group less than 6months $(13.56 \%)$. No grade 3 difficulty in laryngoscopy was seen.

In our study, it was observed that in infants less than 6months of age the parameters of airway assessment correlated better with the weight than the age of the infant. The weight correlated with the difficulty in mask ventilation (p-0.0059). Difficult mask ventilation was associated with high Cormack Lehane grade (p-0.0084) in this age group. Difficulty in mask ventilation was associated with difficult laryngoscopy (p-0.00) and difficulty in laryngoscopy was associated with difficult intubation ( $\mathrm{p}-0.033$ ).

We could not find any literature to collaborate some of our findings as there are limited numbers of studies done in this age group.

Difficulty in mask ventilation, laryngoscopy and intubation was encountered but could be managed due to the presence of experienced anesthetist while anesthetizing children of less than six months.

We recommend that airway assessment, an experienced anesthestist and anticipation of difficult airway is of paramount importance in the age group less than 6 months and further studies are required to be done in this age group to predict difficult airway.

\section{References}

1. Practice guidelines for the management of the difficult airway. An updated report by the American Society of Anaesthesiologists Task Force on Management of the Difficult Airway. Anaesthesiology 2003; 98: 1269

2. Rosenblatt W. The airway approach algorithm. J Clin Anaesthesia 2004; 16: 312

3. Westhorpe RN. The position of the larynx in children and its relationship to the ease of intubation. Anaesthesia Intens Care 1987; 15: 384

4. Dickison AE. The normal and abnormal pediatric airway. Recognition and management of obstruction. Clin Chest Med 1987;8: 583-597.

5. Barach PG, Cullen BF, Stoelting RK, Cahalan MK, Stock MC. Clinical Anesthesia. $6^{\text {th }}$ edition. New Delhi: Wolters Kluwer (India) Pvt Ltd;2009. .

6. Koay CK. Difficult tracheal intubationanalysis and management in 37 cases. Singapore Med J 1998 Mar;39(3):112-4.

7. Ghai OP. Essential paediatrics. Seventh edition. New delhi:CBS publishers,2009.

8. Nafiu OO, Burke CC, Gupta R, Christensen R, Reynolds PI, Malviya S. Association of neck circumference with perioperative adverse respiratory events in children. Pediatrics. 2011 May;127(5): e1198-205.

9. Aggarwal A, Sharma KR and Verma UC. Evaluation of "Difficult Airway Predictors in Pediatric Population" As a Clinical Investigation. J Anesth Clin Res 2012; $3: 11$. 